\title{
Survey of the eventual diagnosis in 600 cases referred for a second histological opinion after an initial biopsy diagnosis of Hodgkin's disease
}

\author{
W. ST. C. SYMMERS, SENR \\ From the Histopathology Laboratories, Charing Cross Group of Hospitals, London ${ }^{1}$
}

SYNOPSIS In a series of 600 cases of lymphadenopathy in which an initial histological diagnosis of Hodgkin's disease was reviewed in a reference laboratory this interpretation was confirmed in 317 cases $(53 \%)$. In the 283 other cases the diagnosis of Hodgkin's disease was considered to bee mistaken. The condition most frequently confused with Hodgkin's disease was chronic non-specifico lymphadenitis. Reticulum cell sarcoma, metastatic tumours, infectious mononucleosis, dermato-pathic lymphadenopathy, toxoplasmosis, and early sarcoidosis were also notably frequent amongs the conditions mistaken for Hodgkin's disease.

The material reviewed in this summary account of errors in the histological diagnosis of Hodgkin's disease and in the complementary paper on the misdiagnosis of reticulum cell sarcoma (Symmers, 1968) has been collected from various sources in the British Isles during a period of 20 years (1947 to 1966 inclusive). Many of the specimens were referred by colleagues who were interested in discussing what seemed to them to be unusual or equivocal histological findings in lymph nodes that nonetheless they had interpreted as justifying a diagnosis either of Hodgkin's disease or of reticulum cell sarcoma. Alternatively, the specimens were sent simply for a second opinion before committing the patients to the consequences of the diagnosis of one or the other of these diseases. Some of the material has been collected through the collaboration of clinical departments, thanks mainly to the custom in most radiotherapy centres of reviewing the histological specimens from all new patients before planning treatment. Finally, some of the cases are from among my own mistakes in biopsy diagnosis.

Histological diagnosis is inevitably liable to error; no one engaged in this work is infallible. It is not the rare or the curious or the atypical histological picture that is likeliest to lead to misinterpretation: instead, as any experienced pathologist would admit, our everyday difficulties are often in relation to the diagnosis of important common conditions. Squamous carcinoma, Hodgkin's disease, tuber-

${ }^{1}$ Address for reprint requests: 30 Sandy Lodge Way, Northwood, Middlesex, England

Received for publication 31 January 1968. culosis, rectal polyps, and malignant melanoma are only five among my personal diagnostic quicksands. as teachers we probably often give students the impression that these are conditions that are recognized easily and with certainty on biopsy; the facts is that histological diagnosis is neither easy nor always certain.

\section{MATERIAL}

The material studied in this paper comprises lymph node biopsy specimens from 600 patients in whom? the diagnosis of Hodgkin's disease had been made histologically, either with conviction or as the. likeliest explanation of the microscopical findings. The diagnosis of Hodgkin's disease was substantiated by review of the histological appearances ando by the course of the disease in 317 cases $(53 \%)$ : in the 283 other cases the original suggestion of Hodg-음 kin's disease was not confirmed; the eventual diagnoses in these cases are shown in Table I.

\section{COMMENT}

It is not appropriate to comment here on the features that determine the histological differen $x$ tiation between Hodgkin's disease and the conditions named in Table I. Some of the mistakes indicated are very difficult to comprehend: for instance, it is hard to see how follicular lymphoma came to be $\frac{0}{-}$ mistaken for Hodgkin's disease (none of the three cases of follicular lymphoma included in Table I $\stackrel{9}{+}$ showed any evidence of the transition to Hodgkin'sô 
TABLE I

EVENTUAL DIAGNOSIS IN 600 CASES OF LYMPHADENOPATHY REFERRED WITH AN INITIAL HISTOLOGICAL DIAGNOSIS OF HODGKIN'S DISEASE (1947 TO 1966 INCLUSIVE)

Eventual Diagnosis Number of Cases

Group A: Hodgkin's disease

Total 317

(a) Ordinary type 269

(b) Indolent type ('Hodgkin's paragranuloma') 23

(c) Nodular sclerosing type

Group B: Other malignant diseases Reticulum cell sarcoma

Metastatic tumours

(a) Squamous carcinoma

(b) Mammary carcinoma

(c) Seminoma

(d) Anaplastic bronchial carcinoma

(e) Melanoma

(f) Anaplastic thyroid carcinoma

(g) Choriocarcinoma

Follicular lymphoma

Burkitt tumour

Letterer-Siwe disease

Total 69

34

(a)

Group C: Inflammatory and other non-neoplastic reactive conditions

Chronic (non-specific) lymphadenitis

Infectious mononucleosis

Total 192

Dermatopathic lymphadenopathy

18

Early sarcoidosis

Brucellosis

. 7

Tuberculous lymphadenitis 6

Drug-induced lymphadenopathy (due to pheny-

toin and related compounds)

Syphilis

(a) Lymphadenitis of primary syphilis

(b) lymphadenitis of tertiary syphilis

Early cat-scratch disease

Metazoan lymphadenitis ('larva migrans')

Mycotic lymphadenitis

(a) Coccidioidomycosis

(b) Histoplasmosis

Leprous lymphadenitis

Measles

Total 3

1

2

Total $\begin{array}{r}2 \\ 2\end{array}$

1

Group D: Miscellaneous disorders involving lymph nodes

\footnotetext{
Storage diseases

(a) Gaucher's disease

(b) Niemann-Pick disease

Macroglobulinaemia (Waldenström)

Amyloidosis

Rheumatoid lymphadenitis

Lymphadenopathy of systemic lupus

erythematosus
}

Group E: Undiagnosed (see text)

(a) Cases with fatal outcome

(b) Cases with recovery

disease that is a very rare occurrence in this condition). Other mistakes are examples of the commonplace pitfalls, explicable by histological appearances that are notoriously liable to delude, or that may even seem exactly to simulate the picture of Hodgkin's disease: for instance, in the delusive first category are toxoplasmosis, early sarcoidosis, and early banal tuberculosis, which with early Hodgkin's disease constitute a quartet of easily confused histological entities (compare Figs. 5.22, 5.60 and 5.85 in Symmers, 1966); in the second and even more dangerous category of near-exact simulants are some cases of the lymphadenitis or brucellosis (see Fig. 5.86 in Symmers, 1966) and of druginduced (phenytoin) lymphadenopathy (see Figs. 5.49 and 5.50 in Symmers, 1966).

TOXOPLASMOSIS Fifteen of the 18 cases of toxoplasmic lymphadenitis that were mistaken for Hodgkin's disease are from the first 14 years (1947 to 1960 inclusive) of the 20 -year period covered by this study; only three date from during the last six years. There can be scarcely a doubt that this is because the infection has become more familiar to histopathologists since 1960 , thanks particularly to the work of Beverley, Caley, and Warrack (1958) and of Stansfeld (1961). Indeed, there is a tendency at present to make the converse mistake and misdiagnose early Hodgkin's disease as toxoplasmosis: the possibility of such an error should be thought of when serological and other laboratory investigations fail to support a histological diagnosis of toxoplasmosis (see Table II).

FOURTEEN CASES OF DOUBTFUL DIAGNOSIS The 14 cases in Table $I$ in which the diagnosis remains doubtful were all examples of histologically pleomorphic lymphoreticular diseases, clearly distinct from Hodgkin's disease both histopathologically and in their clinical presentation and course. No diagnostic label seemed appropriate other than summary histological descriptions of no nosological merit, such as 'giant-celled sinus histiocytosis', 'focal necrotizing tuberculoid lymphadenitis with conspicuous eosinophil aggregates' and 'focal giant cell and reticulum cell hyperplasia of lymph node medulla'. These are all cases in which thorough clinical and laboratory investigation failed to identify the nature of the illness. Seven of the patients died of the disease and seven recovered completely. There was a necropsy in only one case: the postmortem diagnosis was said to be 'atypical Hodgkin's disease', but the pathologist did not keep any tissue for microscopy and his description of the naked-eye appearances gives no hint at all of his reason for suggesting Hodgkin's disease, a diagnosis which probably merely reflected the original and undoubtedly incorrect biopsy impression of 'unusual Hodgkin's disease'. It is interesting to find that in every one of these seven fatal cases the registered cause of death is Hodgkin's disease. A pathologist, disturbed by the inaccuracy in the registration of the cause of death in the cases of two of these patients, discussed it with his clinical colleagues: he tells me that their explanation was that the naming of a 
definite and well-known disease causes less distress and concern to relatives and makes a necropsy unnecessary.

HODGKIN'S DISEASE MISTAKEN FOR OTHER DISEASES This paper is concerned mainly with the histological misinterpretation of other diseases as Hodgkin's disease. The converse error needs a mention too. During the period in which the 600 cases in Table I were collected (1947 to 1966 inclusive), the same reference laboratories received lymph node biopsy specimens from 85 cases that proved to be Hodgkin's disease although originally referred with other histological diagnoses. These diagnoses are indicated in Table II. It is interesting to find that all except cryptococcosis also figure in Table $I$, most of them prominently: in other words, reticulum cell sarcoma, metastatic tumours, and various non-neoplastic conditions, notably chronic lymphadenitis, not only may be mistaken for Hodgkin's disease but may be mistakenly diagnosed instead of Hodgkin's disease, an error that potentially is even more important from the points of view of treatment and prognosis.

All the six cases in Table II in which the histological picture of Hodgkin's disease was at first mistaken for that of toxoplasmosis were seen after 1961.

\section{TABLE II}

ORIGINAL HISTOLOGICAL DIAGNOSIS IN 85 INITIALLY MISDIAGNOSED CASES OF HODGKIN'S DISEASE ${ }^{1}$

\begin{tabular}{|c|c|c|}
\hline Original Diagnosis & Number & of Cases \\
\hline $\begin{array}{l}\text { Malignant diseases } \\
\text { Reticulum cell sarcoma } \\
\text { Metastatic carcinoma }\end{array}$ & $\begin{array}{l}24(4) \\
19(4)\end{array}$ & Total $43(8)$ \\
\hline Non-neoplastic conditions & & Total 42 (17) \\
\hline $\begin{array}{l}\text { Chronic (non-specific) lymphadenitis } \\
\text { Toxoplasmosis (cases all seen since 1961) } \\
\text { Cryptococcosis }{ }^{2} \\
\text { Early sarcoidosis } \\
\text { Dermatopathic lymphadenopathy }{ }^{3}\end{array}$ & $\begin{array}{l}30(12) \\
6(4) \\
2(0) \\
2(1) \\
2(0)\end{array}$ & \\
\hline
\end{tabular}

${ }^{1}$ The first figure after a diagnosis represents the total number of cases of the ordinary and indolent types of Hodgkin's disease together that were originally mistaken for the condition indicated. The figure in brackets represents the number of cases of the indolent type of Hodgkin's disease originally mistaken for the condition indicated.

'In both these cases the patient was indeed suffering from cryptococcosis. The infection presented with meningeal involvement. Through misunderstanding of the relation between cryptococcosis and Hodgkin's disease, histological appearances typical of the latter were wrongly interpreted as a 'Hodgkin's-disease-like reaction to the fungus'. In fact, both were classic examples of the way in which certain chronic systemic diseases of the lymphoreticular system, particularly Hodgkin's disease and sarcoidosis, by altering the patient's resistance predispose to the establishment of infection by certain microorganisms, including Cryptococcus neoformans (Symmers, 1967).

${ }^{3}$ In these two cases generalized chronic erythrodermia had developed as a complication of Hodgkin's disease. In both, the lymph nodes showed changes typical of the ordinary type of Hodgkin's disease as well as those of dermatopathic lymphadenopathy secondary to the skin condition: the appearances due to the former were at first taken to be a manifestation of the latter.
Thus they date from a period by which toxoplasmic lymphadenitis had become a familiar diagnosis in $\overrightarrow{\vec{S}}$ biopsy practice, even if the diagnostic and, particularly, the differential diagnostic snags had not yet become as widely recognized (see comment on toxoplasmosis, above).

SUBDIVISION OF HODGIN's DISEASE The 317 cases of Hodgkin's disease in Table $I$ are subdivided there $\vec{\circ}$ into 269 cases of the ordinary ('classical' or 'granu- $\overrightarrow{\vec{H}}$ lomatous') histological type, 23 cases of the indolent $\vec{\omega}$ ('paragranulomatous') type, and 25 cases of the nodular sclerosing type defined by Lukes (1963). Hitherto, the last of these three types has not been separately designated in published references to the $i$ series of cases of primary malignant and potentially of malignant diseases of the lymphoreticular system studied in Charing Cross Medical School (Table 5.1 in Symmers, 1966). It seems therefore to be desirable to take this opportunity to include an appropriate breakdown of the cases of Hodgkin's disease into these three types as part of an up-to-date retabulation $\rightrightarrows$ of the composition of the series (Table III): the $\mathbb{D}$

TABLE III

CLASSIFICATION OF 1,257 CASES OF PRIMARY MALIGNANT AND POTENTIALLY MALIGNANT DISEASES OF THE LYMPHORETICULAR SYSTEM (1947 TO 1966 INCLUSIVE)

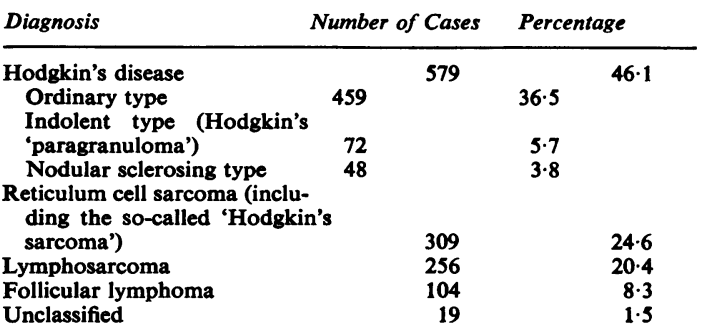

histological criteria for this subdivision do not differ in important details from those adopted by Hanson (1964). Most of the cases designated nodular sclerosing Hodgkin's disease in Table III were formerly included with cases of the ordinary type of the disease (Table 5.1 in Symmers, 1966).

\section{FREQUENCY OF DIAGNOSTIC FAILURE}

The series with which this paper is primarily concerned comprises 600 cases in which the initial 0 lymph node biopsy diagnosis was Hodgkin's $\Phi$ disease: this diagnosis had been made either con- ? fidently or at least with a strong assumption of its accuracy. Eventually, the diagnosis of Hodgkin's disease proved to be wrong in 283 cases: in other words, in $47 \%$ of patients who were initially con- 
sidered to show histological evidence of Hodgkin's disease some other condition was in fact responsible for the lymphadenopathy.

In a series of 459 cases of histologically proven Hodgkin's disease of the ordinary type (Table III) there were 399 cases in which the original biopsy diagnosis was correct. The remaining 60 cases were at first diagnosed histologically as showing other conditions: in other words, there was a failure of the initial biopsy diagnosis in $13 \%$ of cases of ordinary Hodgkin's disease.

In a series of 72 cases of histologically proven Hodgkin's disease of the indolent ('paragranulomatous') type (Table III) there were 48 cases in which the original biopsy diagnosis was correct. The remaining 24 cases were at first misdiagnosed histologically: in other words, there was a failure of the initial biopsy diagnosis in $33 \%$ of cases of indolent Hodgkin's disease. In spite of the characteristic and well-defined microscopical appearances of this condition its recognition still comes less naturally to the microscopist than the recognition of the longfamiliar picture of the ordinary type of Hodgkin's disease.

In a series of 309 cases of histologically proven reticulum cell sarcoma (Table III) the initial biopsy diagnosis was correct in 243. The remaining 66 cases were at first misdiagnosed histologically: in other words, there was a failure of the initial biopsy diagnosis in $21 \%$.

\section{CONCLUSIONS}

The conclusions to be drawn from the experiences included in this paper are straighforward: Hodgkin's disease presents more diagnostic difficulties to the histopathologist than is usually realized, and its differential histological diagnosis should be con- sidered in every case in considerably greater depth than is usual. Formal statistical treatment of the data presented here has not been sought, for it seems that the simple figures sufficiently indicate to the pathologist the quality of the problem that Hodgkin's disease and similar conditions face him with.

Those who recognize their own mistakes in Tables I and II should also note how many mistakes have been made by the rest of us whose work also contributed to the tabulated observations. These lists of errors are not so much a condemnation of our standards of diagnosis as an index of the need not to be complacent about our ability to interpret biopsy appearances well. We must avoid avoidable mistakes: we may be on the way to doing so if we constantly review the reasoning behind our diagnoses and if we regularly consult with other pathologists and with clinicians. A part of the histopathologist's pleasure and satisfaction in his work is the opportunity to discuss it and its problems with others who have the same interests: discussion over the microscope is also an invaluable control of our standards as well as an introduction to new knowledge; above all it is also a means of saving individual patients from the all too real dangers inherent in histological misdiagnosis.

\section{REFERENCES}

Beverley, J. K. A., Caley, J. P., and Warrack, A. J. N. (1958). J. clin. Path., 11, 119.

Hanson, T. A. S. (1964). Cancer (Philad.), 17, 1595.

Lukes, R. J. (1963). Amer. J. Roentgenol., 90, 944.

Stansfeld, A. G. (1961). J. clin. Path., 14, 565.

Symmers, W. St. C. (1966). In Systemic Pathology, edited by G. Payling Wright and W. St. C. Symmers, vol. I, p. 195. Longmans, London.

- (1967). Lancet, 1, 159.

Symmers, W. St. C., Sr (1968). J. clin. Path. 21, 654. 